\title{
A SIMPATIA EM HUME: ENTRE O TRATADO, O CARÁTER NACIONAL E AS FACÇÕES
}

\author{
Dario Galvão ${ }^{1}$
}

Resumo: O presente texto procura percorrer o Tratado da natureza humana (1739-1740) e alguns dos Ensaios morais, políticos e literários tendo como fio condutor o princípio da simpatia em Hume. A partir da enunciação do princípio no Livro II do Tratado, seguimos em especial aos ensaios "Dos caráteres nacionais" (1748) e "Dos partidos em geral" (1741). Sob essa perspectiva, espera-se observar como a simpatia e, por conseguinte, a imaginação podem ser relevantes ao pensamento político e social na filosofia humeana.

Palavras-chave: Simpatia - caráter nacional - facção - imaginação - Hume.

Na Seção XI - Of the love of fame, Parte 1, Livro II do Tratado da natureza bumana, Hume introduz o princípio da simpatia. Durante a investigação das causas do orgulho e da humildade, após estabelecer o que será chamado de causas originais - virtude, beleza, riqueza, e outras ${ }^{2}-$, Hume precisa conciliá-las ao fato de que as opiniões alheias exercem uma poderosa influência sobre esse par de paixões. Segundo o filósofo, essas opiniões - que vai chamar de causa secundária - têm tanta influência sobre os afetos quanto as qualidades relativas as causas originais ${ }^{3}$. Numa passagem posterior, a relação entre esses dois fatores é aludida de maneira ainda mais veemente: o orgulho (assim como uma série de outras paixões) não teria "força alguma, se fizéssemos inteira abstração dos pensamentos e sentimentos alheios" 4 . A pergunta que orienta a introdução do princípio da simpatia é, portanto, a seguinte: dada a constatação da influência, como pode ser que ela ocorra? Ora, para

\footnotetext{
${ }^{1}$ Doutorando em Filosofia pela USP. E-mail: dario.galvao@gmail.com. Orientador: Prof. Dr. Pedro Paulo Pimenta. Este artigo foi composto durante a pesquisa de mestrado que contou com financiamento da Fapesp (proc. no. 2015/14631-0).

2 As causas são abordadas, em termos gerais, desde o início da Parte 1 (Livro II do Tratado); e, em termos particulares, da Seção 7 a 10 dessa mesma parte. Hume costuma elencar essas três qualidades como causas; no entanto, em diversos momentos menciona outras, deixando claro que elas não são as únicas. Por exemplo, cita as qualidades mentais como "espírito, bom-senso, erudição, coragem, justiça integridade"; as qualidades do corpo, "beleza, força, agilidade, boa aparência, talento para a dança, equitação, esgrima, e de sua destreza em qualquer ocupação ou atividade manual"; menciona também "país, família, filhos, parentes, riquezas, casas, jardins" etc. (HUME, Tratado da natureza bumana, p. 313). Quanto ao termo "causas originais", ele surge apenas no final da Parte 1, quando é preciso distingui-las da influência das opiniões alheias.

${ }^{3}$ HUME, Tratado da natureza bumana, p. 350 . As citações ao Tratado referem-se à edição da Unesp, com a tradução de Déborah Danowski.

${ }^{4}$ HUME, Tratado da natureza bumana, p. 397.
} 
respondê-la, essa que é uma questão particular a respeito de um fato específico sobre um único par de paixões, Hume julga necessário fazer um desvio a fim de elaborar a natureza do princípio que explicaria o fenômeno. É nessa Seção XI que encontramos a exposição mais completa sobre a simpatia, apesar de sua presença significativa no Livro III.

No desvio, uma série de fenômenos é trazida à tona. Seu primeiro parágrafo é extremamente rico sob esse aspecto: diversos casos são apresentados a fim de dar evidência ao que Hume chama inicialmente de "nossa propensão a simpatizar com os outros e a receber por comunicação suas inclinações e sentimentos"5. Primeiro, Hume refere-se à facilidade com que uma criança aceita prontamente as opiniões que lhe são propostas e à análoga influência que um adulto sofre de seus companheiros de dia a dia. No caso do adulto, o filósofo observa que, mesmo não sendo tão suscetível quanto a criança, por mais "discernimento e inteligência" que tenha, dificilmente consegue "seguir sua própria razão ou inclinação quando esta se opõe a de seus amigos" ${ }^{6}$. Em seguida, ampliando o universo de análise, Hume afirma ser efeito da simpatia a uniformidade de humores e modos de pensar entre as pessoas de uma mesma nação, rejeitando a hipótese que a atribui ao solo ou o clima7, "os quais, mesmo que continuem invariavelmente iguais, são incapazes de manter o caráter de uma nação igual por todo um século"8.

Ainda no primeiro parágrafo, menciona-se também a infusão de humores na relação entre indivíduo e grupo: o primeiro assume facilmente o humor do segundo, "uma expressão alegre inspira [infuses] uma sensível satisfação e serenidade a minha mente, ao passo que uma expressão raivosa ou triste causa-me um súbito desalento"'. Ao final, numa importante passagem, Hume apresenta uma enumeração de paixões - "ódio, ressentimento, estima, amor, coragem, alegria e melancolia" - e defende que todas elas seriam sentidas "mais por comunicação" do que por um temperamento e disposição naturais ${ }^{10}$. Nesse caso, é a própria produção das paixões em geral que parece servir de suporte, no plano da experiência, para a enunciação da simpatia.

Se observarmos bem, notaremos que, apesar da semelhança, trata-se de situações relativamente diferentes entre si. A começar pelos elementos envolvidos na comunicação: considerando apenas esse primeiro parágrafo, temos inclinações, sentimentos, opiniões, humores ou temperamentos, modos de pensar [turn of thinking], assim como a referência a uma série de paixões. Em outros momentos, veremos que, além desses, a comunicação também é de afetos e emoções. ${ }^{11}$ Interessante notar que a adoção de opiniões alheias e a infusão de sentimentos são elencadas como fenômenos de um mesmo princípio. Essa equivalência entre pensamento e

\footnotetext{
5 HUME, Tratado da natureza bumana, p. 351.

6 Id., ibid.

7 Tema principal do ensaio "Dos caráteres nacionais" (1748).

8 Id., ibid.

9 Id., ibid.

${ }^{10} I d$., ibid.

11 Ver por exemplo HUME, Tratado da natureza bumana, p. 353, 389 e 399.
} 
sentimento como elementos da simpatia, por assim dizer, permanece constante e evidente ao longo de todo o livro. Por exemplo, numa passagem do Livro III, Hume escreve:

Tão estreita e íntima é a correspondência entre as almas dos homens que, assim que uma pessoa se aproxima de mim, ela me transmite [diffuses] todas as suas opiniões, influenciando meu julgamento em maior ou menor grau. Embora, muitas vezes, minha simpatia por ela não chegue ao ponto de me fazer mudar inteiramente meus sentimentos e modo de pensar, raramente é tão fraca que não perturbe o tranquilo curso de meu pensamento, dando autoridade à opinião que me é recomendada por seu assentimento e aprovação. Pouco importa sobre que assunto ela e eu estamos pensando. ${ }^{12}$

Sentimentos e opiniões (ou modos de pensar) caminham lado a lado no ato de simpatia, o que parece estar de acordo com a maneira singular como Hume concebe a diferença entre ideia e impressão, fundamental à sua filosofia. Elas não se distinguem por natureza, mas por graus de vivacidade [iveliness], sendo que uma pode transformar-se na outra com relativa facilidade ${ }^{13}$. Além disso, o conceito de crença [belief], referido também como opinião ${ }^{14}$ no Livro I, aponta à mesma direção, já que Hume o concebe como um modo particular de sentir uma ideia ${ }^{15}$. Em ambos os casos vemos juízo e sentimento articularem-se de modo conjugado e estreito. Hume define "opinião ou crença" da seguinte forma: "uma ideia vívida relacionada ou associada a uma impressão presente"16. Assim, um juízo é visto como uma maneira particular de se conceber um objeto (elevado grau de vivacidade na mente em virtude da relação do objeto com uma impressão). ${ }^{17}$ Sob essa perspectiva, considera-se que as opiniões difundem-se à maneira dos sentimentos, ou seja, através do mesmo princípio: há um contágio de opiniões, cujo interesse para o pensamento político não parece ser pequeno.

Vejamos como, no ensaio "Dos caráteres nacionais" (1748), é possível encontrar pontos relevantes para pensarmos a amplitude dos fenômenos atribuídos à simpatia - e assim começamos a observar a presença desse princípio no pensamento político de Hume posterior ao Tratado. ${ }^{18}$ Nesse

${ }^{12} I d .$, p. 632

${ }_{13}$ Id., p. 353.

${ }^{14}$ Id., p. 125.

15 Id., p. 127.

${ }_{16} I d$. p. p. 125.

${ }^{17}$ Jacqueline Taylor chama a atenção para a importância de se considerar a comunicação de opiniões, ou sympathy with belief, usualmente negligenciada pelos intérpretes segundo a autora (TAYLOR, "Sympathy, Self, and Others", p. 194). Árdal, contudo, não deixa de observar este ponto (ÁRDAL, Passion and Value in Hume's Treatise, p. 47).

18 Apesar da importância que a simpatia adquire nos livros II e III do Tratado, sabe-se que há uma mudança de cenário na Investigação sobre os princípios da moral (1751). Não nos interessa aqui discutir isso. Esperamos, ao 
ensaio, Hume percorre uma longa série de povos, entre antigos e modernos, e reconhece que há, em cada um deles, um conjunto peculiar de maneiras, que seria efeito não de causas físicas, mas de "uma simpatia ou contágio de maneiras [manners]"19. O fato de estarem submetidos a um mesmo governo, por exemplo, é visto como um fator importante na produção da similitude observada entre os indivíduos. Isso ocorre, principalmente, porque, unidos num mesmo corpo político, "as ocasiões de intercurso são tão frequentes, para sua defesa, comércio e governo, que, aliadas a uma fala ou língua comum, adquirem maneiras semelhantes e um caráter comum ou nacional, bem como um caráter pessoal peculiar a cada indivíduo"20. A leitura desse trecho, e do escrito como um todo, nos sugere que as maneiras, os hábitos e os costumes devem ser considerados como elementos passíveis de serem difundidos via simpatia, e portanto podemos acrescentá-los à lista citada acima, que compreende os diferentes elementos comunicados por meio desse princípio.

De modo semelhante ao que vemos no Tratado, a simpatia no ensaio é comumente referida por meio da ideia de comunicação. Em última análise, é através dela que se dá a composição - Hume usa o termo composition ${ }^{21}$ - das diversas disposições em uma unidade comum: o caráter da nação. É pela comunicação que uma forma de governo espalha [spread] um conjunto peculiar de maneiras 22 ou que os costumes de um povo misturam-se [mixture] a outros com que mantém contato, alterando-se ${ }^{23}$. O contato, ou seja, as "ocasiões de intercurso" seria o meio pelo qual a comunicação ocorreria, provocando uma verdadeira transferência de modos de vida.

O ensaio segue os passos do que foi estabelecido no Tratado, remetendo o fenômeno a uma propensão da natureza humana:

A mente humana é de uma natureza muito imitativa; nem é possível que grupos de homens conversem entre si sem que adquiram uma similitude de maneiras e comuniquem entre si seus vícios e suas virtudes. A propensão para a companhia e a sociedade é poderosa em todas as criaturas racionais; e a mesma disposição que nos dá essa propensão faz-nos compartilhar profundamente dos sentimentos dos

\footnotetext{
final deste texto, ter mostrado certos casos, nos Ensaios morais, politicos e literários, em que a simpatia aparece de maneira significativa. Como é de se esperar, não vemos nos ensaios passagens sobre o mecanismo da simpatia, profundamente vinculado à teoria da imaginação, tal como vemos no Tratado - o que orienta a presente leitura dessa última obra, guardando o exame do mecanismo para outro momento.

19 HUME, "Of National Characters", In: HUME, Essays, Moral, Political and Literary. Ed. Eugene F. Miller. Indianapolis: Liberty Fund, 1987, p. 204.

20 HUME, "Dos caráteres nacionais", In: HUME, Ensaios politicos. Trad. Pedro Paulo Pimenta. São Paulo: Martins Fontes, 2003, p. 103.

${ }^{21}$ HUME, "Of National Characters", p. 203.

${ }^{22}$ Id., p. 207.

${ }^{23}$ Id., p. 206.
} 
outros, o que é a causa para que paixões e inclinações similares percorram como que por contágio um grupo ou um punhado [club or knot] de pessoas. ${ }^{24}$

Ainda que o trecho em questão volte-se principalmente ao tema do caráter das nações - e por isso realce o aspecto imitativo do fenômeno - não há dúvida de que o princípio é o mesmo que aquele apresentado no Livro II do Tratado. Lá também se trata de "entrar profundamente nos sentimentos uns dos outros" 25 e da consequente produção de paixões semelhantes, que no ensaio é referida em momentos decisivos por contágio. No Tratado, entretanto, esse termo sequer aparece no Livro II, encontrando-se apenas no Livro III, numa referência à simpatia. ${ }^{26}$ Apesar disso, tanto a definição inicial do princípio - "a propensão a simpatizar com os outros e a receber por inclinação seus sentimentos e inclinações" 27 -, quanto os fenômenos elencados (por exemplo, a infusão do humor do grupo no indivíduo), remetem-nos à ideia de contágio, tal como vemos no ensaio em questão. ${ }^{28}$ Outro paralelo entre os dois textos é o vínculo estreito entre a comunicação e a propensão à companhia ou à sociedade, que pode ser visto em passagens importantes sobre a simpatia no Tratado29.

A comunicação de vícios e virtudes, mencionada no trecho supracitado do ensaio, está associada à comunicação de maneiras e é outro tema que se encontra no interior do Tratado, assim como na Investigação sobre os princípios da moral (1751) - doravante Investigação. Esse ponto relaciona-se à crítica de Hume a um tipo particular de ceticismo: aquele que restringe a origem de todos os juízos morais apenas à educação e a arte dos políticos ${ }^{30}$. Por meio da eloquência, ou mesmo da opinião alheia, uma ideia de bem ou mal, "que de outro modo seria inteiramente negligenciada", passa a ter influência sobre o indivíduo ${ }^{31}$. Há, nesse sentido, uma comunicação ou simpatia de virtudes e vícios que se assemelha ao contágio. ${ }^{32}$

\footnotetext{
${ }^{24}$ Id., p. 103.

${ }^{25}$ HUME, Tratado da natureza bumana, p. 354.

26 "As paixões são tão contagiantes que passam com a maior facilidade de uma pessoa a outra, produzindo movimentos correspondentes em todos os corações humanos.” (HUME, Tratado da naturęa bumana, p. 644)

${ }^{27}$ HUME, Tratado da natureza humana, p. 351.

${ }^{28}$ A equivalência entre simpatia e contágio é vista também em duas ocasiões na Investigação sobre os princípios da moral (HUME, Investigação sobre os princípios da moral, p. 324 e 333). As referências a essa obra consideram a edição da Unesp, tal como indicado nas referências bibliográficas abaixo.

${ }^{29}$ Por exemplo: HUME, Tratado da natureza humana, p. 397.

${ }^{30}$ HUME, Tratado da natureza humana, p. 618; Investigação sobre os princípios da moral, p. 279.

31 HUME, Tratado da natureza bumana, p. 462.

32 Política e educação exprimem também uma influência que ocorre por comunicação de paixões e imitação. Um discurso eloquente produz a propagação das opiniões ou do modo de julgar exposto pelo orador, e determinadas ideias de bem ou mal passam a ter influência, ou seja, ganham autoridade no espírito dos espectadores. O maior ou menor grau desse espalhamento depende diretamente do quanto a plateia aprofunda-se nos sentimentos e opiniões daquele que discursa, ou seja, do quanto ela é contagiada. Quanto à educação, J. B. Stewart, em seu clássico “The Moral and Political Philosophy of David Hume” (1963), dedica
} 
Hume reconhece a "poderosa influência" dos fatores sociais na constituição dos juízos morais - tal como defendem os céticos em questão - contudo não admite que a origem da moralidade possa ser reduzida a eles. Segundo o filósofo, "se os homens não tivessem um sentimento natural de aprovação e reprovação, este nunca poderia ser despertado pelos políticos; e as palavras lowvável, elogiável, condenável e odioso seriam tão pouco inteligíveis como se pertencessem a uma língua inteiramente desconhecida de nós"33. Ou seja, Hume concorda com a força da comunicação no que tange a determinação de virtudes e vícios entre os homens de uma mesma sociedade, porém insiste que ela não pode prescindir de "sentimentos naturais". Na Investigação, entretanto, ao elaborar a mesma crítica, Hume vai um pouco além na consideração dessa força e, ao pensar sobre a relação entre preceito, educação e certo "princípio natural subjacente", reconhece a possibilidade de que, em alguns casos, novos sentimentos sejam criados para além do que poderia ser considerado "natural".

E, na verdade, deve-se reconhecer que esse princípio de preceito e educação tem uma poderosa influência, na medida em que pode frequentemente ampliar ou diminuir os sentimentos de aprovação e desagrado para além de seus padrões naturais; e, em certos casos particulares, pode até mesmo criar um novo sentimento desse tipo sem nenhum princípio natural subjacente, como é evidente em todas as práticas e rituais supersticiosos. Mas que toda estima e reprovação morais brotem dessa origem, isso é algo que nenhum investigador judicioso irá certamente admitir. ${ }^{34}$

um capítulo às paixões e à ação, no qual encontramos uma breve interpretação a respeito de educação e simpatia: "As duas causas morais [em oposição às causas físicas, como o clima por exemplo], educação e simpatia, trabalham juntas; de fato, muito do impacto da educação deriva da simpatia. Contudo, enquanto a educação preocupa-se principalmente em estabelecer opiniões, que podem ou não estar corretas, por meio da formação dos mais jovens para associar certas ideias, isto é, para pensar de certas maneiras, a simpatia comunica sentimentos, basicamente sentimentos de aprovação ou desaprovação. Simpatia é, portanto, um guia e controle mais sutil e ubíquo." (STEWART, The Moral and Political Philosophy of David Hume, p. 67) Vale observar que, embora Stewart reconheça ser a simpatia o princípio responsável pelo maior impacto da educação, o autor parece restringir a primeira à comunicação de paixões, atribuindo o estabelecimento de opiniões à educação apenas. Isso aparenta estar parcialmente de acordo com o texto de Hume: por um lado, escreve o filósofo que "a educação fixa [infixes] qualquer opinião” (HUME, Tratado da naturez̧a bumana, p. 152, trad. adaptada), portanto a relação entre educação e opinião ressaltada pelo autor procede; entretanto, por outro lado, não se pode ignorar que a simpatia consiste também em comunicação de opiniões e modos de pensar, e, portanto, educação e simpatia parecem estar ainda mais misturadas que Stewart supõe.

33 HUME, Tratado da natureza humana, p. 618.

34 HUME, Investigação sobre os princípios da moral, p. 279. 
Isso nos remete ao apêndice "Um diálogo" 35, ao final da Investigação, onde vemos os interlocutores chegarem a um consenso acerca da religião ser um modo de vida artificial, cujos padrões de comportamento podem apresentar-se absolutamente distintos do resto da humanidade, "e os princípios naturais de sua mente não operam com a mesma regularidade que apresentariam se fossem deixados a si mesmos" 36 . A superstição submete seus seguidores a regras de conduta tão austeras, que fogem das "máximas da razão comum [common reason]" 37, superando até mesmo a intensa diversidade observada ao longo das diferentes épocas e nações (tema brilhantemente desenvolvido ao longo do diálogo em questão), por si só bastante surpreendente.

Dessa diversidade, no diálogo, Hume é capaz de extrair princípios comuns (abstratos), a partir dos quais consolida-se sua apreensão do que seria natural ao ser humano. A religião, porém, não seria passível de ser compreendida por esse meio; tampouco seria o entusiasmo filosófico entre os antigos, uma espécie de correlato da religião moderna segundo a presente perspectiva. $\mathrm{Na}$ antiguidade, é a filosofia que assume a tarefa de regular a conduta cotidiana dos indivíduos, e o entusiasmo atua de tal forma que costumes artificiais são produzidos ${ }^{38}$. Tanto um quanto o outro seriam artificiais na medida em que apresentam uma regularidade própria, que excede e, até mesmo, contraria aquela encontrada entre os indivíduos.

No diálogo, Hume expõe seus princípios gerais da moral, revelados desde o terceiro livro do Tratado: toda virtude é uma qualidade agradável ou útil à própria pessoa que a possui ou a outro; todo vício, por sua vez, desagradável ou prejudicial ${ }^{39}$. São abstratos no sentido de que o modo como se realizam a agradabilidade e a utilidade é indefinido, tendo em vista que dependem sempre das circunstâncias em que se realizam. A diversidade é explicada pelas "diferentes perspectivas que as pessoas adotam sobre essas circunstâncias" 40 , ou seja, sobre o que é útil e o que é agradável ${ }^{41}$. Um mesmo comportamento pode ser louvado num país e ao mesmo tempo desprezado em outro: esse é o caso do luxo, como escreve Hume, cujo efeito é "nocivo e pernicioso em um nativo da Suíça", mas é capaz de "promover as artes e encorajar a diligência em um francês ou inglês" 42 . Para

\footnotetext{
35 Esse apêndice contribui bastante para a interpretação de que os juízos morais são comunicados, de modo análogo às maneiras, os hábitos e os costumes, como visto no ensaio "Dos caráteres nacionais". Os juízos morais são considerados modos de pensar (ou sentimentos) relativos à moral e portanto não há por que não compreendê-los como infundidos por simpatia.

${ }^{36}$ HUME, Investigação sobre os princípios da moral, p. 438.

${ }^{37}$ Id., ibid.

38 Id., p. 435.

${ }^{39}$ HUME, Tratado da natureza humana, p. 630; Investigação sobre os principios da moral, p. 347.

${ }^{40}$ HUME, Investigação sobre os princípios da moral, p. 430.

41 Sobre esse ponto, a metáfora dos rios é bem interessante: "O Reno corre para o norte, o Ródano para o sul; contudo, ambos nascem na mesma montanha e seus percursos opostos são afetados pelo mesmo princípio de gravidade. As diferentes inclinações do solo sobre o qual correm causam toda a diferença em seus cursos." (HUME, Investigação sobre os princípios da moral, p. 426)

${ }^{42}$ HUME, Investigação sobre os princípios da moral, p. 431.
} 
Hume, um importante fator de variação é a diferença entre guerra e paz. Em tempos de desordem, as virtudes militares são mais celebradas que as pacíficas. Aliás, uma mesma virtude, por exemplo a coragem, parece alterar-se entre os dois casos: a coragem necessária à batalha não é a mesma que se espera com relação à lenta aproximação da morte ${ }^{43}$. Apesar da variação, o princípio conserva-se.

Sob essa perspectiva, o fator da natureza, cerne da crítica humeana contra o cético citada acima, expressa-se a partir da constatação desses princípios gerais da moral, que, por sua vez, são produtos não de uma apreciação intuitiva e estática sobre o ser humano, mas da observação de uma regularidade, de um "curso geral das coisas", tal como pode ser apreendido no cotidiano e na história. ${ }^{44} \mathrm{~A}$ natureza humana seria, portanto, uma tendência geral, cuja compreensão não pode se furtar de maneira alguma do exame das circunstâncias. ${ }^{45}$ Assim, o caráter artificial da religião e do entusiasmo filosófico significaria a fuga dessa tendência geral, tendo em vista que seus costumes distanciam-se largamente daquilo que pode ser compreendido a partir dos princípios mais naturais ou usuais. Por alguma razão, outros fatores prevaleceram. Essa razão pode ser encontrada na preponderância exacerbada do fator da comunicação - educação e política -, através do qual sentimentos de aprovação e desaprovação extraordinários são produzidos - o que não significa que, mesmo no que seria considerado um modo de vida "natural", a influência da comunicação deva ser pequena, como reconhece o próprio filósofo.

Em suma, no tema da comunicação dos juízos morais encontramos uma faceta significativa da presença da simpatia no pensamento político humeano. Esse tema estende-se também, nos ensaios, à maneira como Hume concebe as facções, o que sugere, por si só, a pertinência de considerar o princípio de comunicação quando se trata de examinar estas últimas. Segundo o filósofo, quando os homens atuam em facções, o espírito humano revela uma grande contradição, algo que ecoa a crítica vista acima a respeito da religião e do entusiasmo filosófico antigo - ora, na época as facções políticas eram sobretudo facções religiosas.

Não há, na verdade, nenhum outro ponto como esse em que, à primeira vista, pareça haver maior contradição na ordenação da mente humana. Quando atuam em facções, os homens tendem a negligenciar, sem vergonha ou remorso, todos os elos de honra e moralidade para servir a seu partido; e, ainda assim, quando uma facção se forma em torno de uma questão de direito e princípio, não há melhor

\footnotetext{
${ }^{43}$ Id., ibid.

${ }^{44}$ Sobre isso, conferir os parágrafos iniciais do ensaio "Do comércio" (1752). Neles, Hume chama a atenção para a natureza do trabalho filosófico, que seria a de distinguir, numa diversidade enorme de circunstâncias, as que são comuns a todos os casos e as que são supérfluas. Sob essa perspectiva, o princípio é como um espelho da experiência, cuja força depende justamente da capacidade do observador em fazer a distinção.

45 Enquanto, por um lado, o artificial é o prolongamento do natural (HUME, Tratado da natureza humana, p. 513); por outro, o natural não está além das circunstâncias. Sobre isso, conferir o capítulo "Social Experience and Human Nature" em FORBES, Hume's Philosophical Politics, 1975.
} 
ocasião para que os homens descubram uma maior obstinação e um maior senso de justiça e equidade. A disposição social dos homens é a causa comum a essas aparências contraditórias. ${ }^{46}$

Seja na facção seja na religião ${ }^{47}$ parece haver a negligência de princípios gerais da moralidade, em benefício de um modo de conduta exterior, superior, que deve ser seguido a todo custo. Nas facções, o "maior senso de justiça e equidade" encontra, como na religião, um fator determinante na comunicação. Isso é de se esperar, uma vez que, como Hume deixa claro no Tratado, tanto o acordo quanto o desacordo de opiniões entre os homens ocorrem por meio da simpatia. ${ }^{48}$ Não há surpresa, portanto, que esse princípio da imaginação esteja presente nos ensaios sobre as facções, embora não seja nominalmente mencionado.

Tal é, contudo, a natureza da mente humana, que ela sempre apreende toda outra mente que dela se aproxime [it always lays hold on every mind that approaches it; e, assim como é imensamente revigorada por uma unanimidade de sentimentos, assim também fica chocada e perturbada com toda e qualquer contrariedade. Daí a acerbidade que a maior parte das pessoas mostram numa disputa, e sua oposição impaciente mesmo às opiniões mais especulativas e indiferentes. ${ }^{49}$

A mera oposição de opiniões, por si só, já configura um motivo suficiente para que os homens entrem em disputa e atuem em facção. Segundo Hume, isso pode ocorrer mesmo no caso em que não há "contrariedade de ação", isto é, quando, à primeira vista, seria plenamente possível que os dois lados seguissem seus caminhos em paz, dado que não haveria, supostamente, motivo algum para interferirem-se entre si. A contrariedade de ação é vista, por exemplo, numa disputa

46 Hume, "Dos princípios primeiros de governo", In: HUME, Ensaios políticos. Trad. Pedro Paulo Pimenta. São Paulo: Martins Fontes, 2003, p. 22.

47 Apesar das facções políticas serem, na época, facções religiosas, pode-se observar que em diversos momentos Hume concebe as facções do ponto de vista estritamente político, por exemplo, como vemos nos ensaios "Dos primeiros princípios do governo" e "Dos partidos em geral", ambos de 1741.

48 HUME, Tratado da natureza humana, p. 632. Sobre a comunicação inerente ao desacordo: "Pois podemos notar que, quando uma pessoa se contrapõe a mim em uma opinião a que estou fortemente apegado e desperta minha paixão em virtude dessa contradição, sempre sinto por ela um certo grau de simpatia, e é a isso que se deve minha comoção. Observamos aqui um evidente conflito ou choque entre princípios e paixões opostos. [...] Os sentimentos alheios nunca poderiam nos afetar se não se tornassem, em certa medida, nossos sentimentos; e, nesse caso, eles agem sobre nós combatendo e intensificando nossas paixões, como se tivessem sido originalmente derivados de nosso próprio caráter e disposição." (HUME, Tratado da natureza bumana, p. 632)

${ }^{49}$ HUME, "Dos partidos em geral", In: $A$ arte de escrever ensaio e outros ensaios. Trad. e org. Marcio Suzuki e Pedro Paulo Pimenta. São Paulo: Iluminuras, 2011, p. 46. 
sobre qual família deverá assumir o trono: a divisão que segue essa discórdia é mais fácil de ser explicada, segundo Hume, pois ambos os lados desejam ver a sua opinião realizada, e isso não pode se dar ao mesmo tempo. O caso em que não há contrariedade de ação, cujo exemplo mais acabado seriam as controvérsias religiosas, carece desse tipo de propósito. A oposição de opinião é tão perturbadora, ou seja, a comunicação é tão forte, que uma simples discordância teórica vai provocar loucura, choque e fúria; e daí seguem-se as divisões mais fatais e infelizes, segundo o filósofo ${ }^{50}$.

$\mathrm{O}$ acordo e o desacordo que geram as facções são de princípios, mas também de paixões. ${ }^{51}$ Há unanimidade e contrariedade de sentimentos. Ao ardor e a impaciência suscitadas pela oposição, soma-se a produção de afeto e animosidade em cada um dos lados em disputa.

Depois que se alistam em lados opostos, os homens são contagiados de afeto [contract an affection] pelas pessoas a que estão unidos, e de animosidade contra seus antagonistas. E eles frequentemente transmitem essas paixões à posteridade. ${ }^{52}$

Essa condição passional, determinada pelo pertencimento a uma facção, sugere algo importante a respeito do próprio funcionamento desta última: há uma influência mútua que seus membros exercem uns sobre os outros, análoga ao que foi visto acima a respeito da uniformidade de caráter de uma nação. Aqui, a força das paixões envolvidas tende a intensificar o processo de influência. Se a frequentação ou convivência tem o efeito de produzir uma uniformidade no plano nacional, por que não haveria de produzi-la num grupo menor que se articula politicamente?

No ensaio sobre o caráter das nações, a uniformidade em grupos menores é abordada por Hume ao considerar o caráter das profissões. Este seria resultado do fato de que os indivíduos dedicados ao mesmo ofício estariam expostos a uma série de circunstâncias semelhantes, que são particulares a cada profissão. Traços semelhantes são produzidos, pois as circunstâncias alteram de forma equivalente "até mesmo a disposição que os indivíduos recebem das mãos da natureza" 53 . Por exemplo, quanto aos soldados, sua vida incerta torna-os "pródigos e generosos, além de valentes" 54 . Os padres, já que precisam a todo momento passar a impressão de grande devoção, fervor e seriedade, inevitavelmente desenvolvem um caráter dissimulado, haja vista que não há

\footnotetext{
50 HUME, "Dos partidos em geral", p. 46.

51 Hume distingue as facções entre pessoais e reais, sendo que as primeiras são formadas principalmente por amizades ou animosidades pessoais e as segundas por desacordo real de sentimento ou interesse (HUME, "Dos partidos em geral", p. 42). Consideramos, por enquanto, esses dois fatores em conjunto, pois, como afirma o próprio Hume: "raramente se encontram partidos, quer de um gênero, quer do outro, puros e sem mistura.” (ibid., p. 42). Mais à frente, Hume defende que a determinação do tipo de facção dá-se pela prevalecência de um ou outro princípio.

52 HUME, "Dos partidos em geral", p. 44.

${ }^{53}$ HUME, "Dos caráteres nacionais", p. 99.

${ }^{54}$ Id., ibid.
} 
homem que tenha tais qualidades no grau e na constância que a profissão exige ${ }^{55}$. Assim como o padre e o soldado, os políticos unidos a uma facção também estariam sujeitos a condições particulares a essa atividade (análoga ao "ofício").

Sobre a divergência passional entre as diferentes facções, pode-se pensar também nos termos de uma influência que se estabeleça pela convivência. No referido ensaio, Hume explica que a simples união de diferentes indivíduos em um corpo político (aqui compreendido como nação) produz o contágio de maneiras e modos de pensar. A amplitude observada no fenômeno da uniformidade (da nação à profissão), conjugada à explicação de sua origem (circunstâncias particulares e frequentação), permite-nos pensar sobre uma unidade de disposição produzida no interior de cada facção. De fato, Hume faz análises detidas sobre o caráter dos partidos Whig e Tory no ensaio "Dos partidos da Grã-Bretanha" (1741), referindo-se às inclinações predominantes de cada um. ${ }^{56}$ No mesmo sentido, o filósofo afirma que o "gênio de uma seita ou religião particular também tende a moldar os costumes de um povo" ${ }^{57}$. Assim, vemos que a própria natureza dos princípios compartilhados por uma facção pode provocar uma influência importante na uniformização entre os homens que nela atuam.

Considerando a unidade de disposição produzida no interior de uma facção, ressalta-se a relevância que o princípio da simpatia parece ter na filosofia humeana segundo o ponto de vista social. A força desse princípio deve ser reconhecida em toda manifestação de uniformidade, em que indivíduos compõem-se em grupos, e passam a compartilhar opiniões, visões de mundo, paixões, disposição, caráter etc. Aparece, assim, como um fator de produção de regularidades, frutos da mistura ou composição de diferentes ingredientes, com a predominância de alguns em particular. A uniformidade de caráter está associada a uma de paixões, ambas reconhecidas na nação, profissão, facção, ou até mesmo, em uma época, conforme vemos abaixo:

quando causas geram uma inclinação ou paixão particular, em certo momento e em certo povo, ainda que muitos indivíduos escapem ao contágio e sejam comandados por paixões que lhes sejam peculiares, a multidão certamente será tomada pela afecção comum, e por ela governada em todas as suas ações. ${ }^{58}$

\footnotetext{
${ }^{55}$ Id., p. 100.

56 Sobre isso, segue um trecho do referido ensaio, excluído por Hume na revisão de 1770: "É importante notar que, embora os princípios Whig e Tory fossem ambos de uma natureza composta; os ingredientes que predominavam em cada um não eram correspondentes entre si. Um Tory amava a monarquia e nutria afeição pela família Stuart; esta última sendo a afeição predominante do partido. Um Whig amava a liberdade e era amigo da linhagem protestante; mas o amor à liberdade era declaradamente seu afeto predominante." (HUME, Essays, Moral, Political and Literary, p. 613)

${ }^{57}$ HUME, Essays, Moral, Political and Literary, p. 207.

${ }^{58}$ HUME, "Do surgimento e progresso das artes e ciências", In: $A$ arte de escrever ensaio e outros ensaios. Trad. e org. Marcio Suzuki e Pedro Paulo Pimenta. São Paulo: Iluminuras, 2011.
} 
Dito isso, cabe questionar-se sobre as leituras que encaram a simpatia como um princípio de efeito curto e restrito. Do ponto de vista do indivíduo que simpatiza apenas com aqueles em quem é capaz de reconhecer alguma semelhança, pode ficar a impressão de que a simpatia não vai muito longe. No entanto, enquanto princípio de contágio e produção de uniformidades o seu efeito parece ser inimaginável. Ora, só ela seria capaz de preservar o caráter de uma nação por um século e depende dela a prevalecência de certa paixão numa época. ${ }^{59}$ A consideração desses efeitos mais amplos, cuja importância é evidente no âmbito político, não pode dispensar um exame que se concentra no indivíduo.

O estudo do mecanismo da simpatia tal como encontramos no Tratado revela um tipo de influência entre homens cuja ordem ancora-se na imaginação: a simpatia é a comunicação de sentimentos e opiniões a partir de uma associação de ideias. A conversão da ideia do sentimento do outro em sentimento meu ocorre em virtude da associação entre a ideia de eu e a de outro, compreendida como uma transferência de vivacidade entre essas duas percepções. ${ }^{60}$ Há uma tendência da mente a passar do eu ao outro (e assim afetar-se por aquilo que é reconhecido na alteridade), e para entender como e por que essa passagem ocorre é preciso investigar a fundo o que significam os princípios de associação em Hume. Eles exprimem uma naturalidade do pensamento, cujas leis distinguem-se daquelas segundo as quais estamos acostumados a conceber a racionalidade - estamos diante, aqui, da importância do hábito e do prazer como princípios da imaginação, algo que não será desenvolvido neste texto. ${ }^{61}$

Assim, observar a presença da simpatia no pensamento político de Hume permite conceber que há uma "racionalidade escondida" que se revela importante para a consideração das mais diversas dinâmicas políticas e sociais. São leis que operam, em certo sentido, à revelia do sujeito, haja vista que as associações da imaginação ocorrem, segundo o filósofo, de forma secreta e calma no pensamento ${ }^{62}$. Nesse sentido, a imaginação toma o lugar da razão enquanto princípio a partir do qual se pode compreender, por exemplo, como se dá a composição de um corpo político.

Quais fatores são determinantes para que a simpatia ocorra? Ou seja, de que maneira ocorre o contágio? Quão profundos são os sentimentos decorrentes da comunicação e por que ganham tanta força na mente humana? Essas são apenas algumas das questões que têm repercussão no pensamento político e que dependem da investigação da natureza da imaginação para que possam ser devidamente apreciadas. Enfim, parece que tanto a simpatia quanto a imaginação mostram-se objetos de um estudo ao qual o cientista político não pode se furtar.

\footnotetext{
${ }^{59}$ É bom lembrar que a simpatia não se restringe aos homens: Hume considera o mesmo efeito nos animais nestes também é a simpatia que anima todas as paixões (HUME, Tratado da natureza humana, p. 432).

60 HUME, Tratado da natureza humana, p. 351.

$61 \mathrm{O}$ exame da simpatia sob o ponto de vista de seu mecanismo, profundamente vinculado à teoria da imaginação em Hume, foi realizado em minha dissertação de mestrado "Identidade pessoal e simpatia no Tratado de Hume", defendida em 2018 no Departamento de Filosofia da USP.

${ }^{62}$ HUME, Tratado da natureza bumana, p. 368.
} 


\section{SYMPATHY IN HUME: BETWEEN THE TREATISE, THE NATIONAL CHARACTER AND FACTIONS.}

Abstract: The article tries to contribute to the understanding of Michel Foucault's analysis on the relation between forms of exercising power and forms of resistance. The resistance issue is taken as the guideline to analyse a series of notions like: revolution, relations of power, "counter-conducts", up-risings, struggles. This study about resistance makes possible the discussion on the issue of subjectivity in contemporary societies, since a foucauldian perspective.

Keywords: revolution - resistance - "counter-conducts" - up-risings - struggles.

\section{Referências bibliográficas:}

HUME, D. Treatise of Human Nature. Ed. David Fate Norton e Mary J. Norton. Oxford: Clarendon Press, 2011. (Trad. Déborah Danowski. São Paulo: Ed. Unesp, 2000).

An Inquiry Concerning the Principles of Morals. Ed. Tom L. Beauchamp. Oxford: Clarendon

Press, 1998. (Trad. José Oscar de Almeida Marques. São Paulo: Ed. Unesp, 2003)

. Essays, Moral, Political and Literary. Ed. Eugene F. Miller. Indianapolis: Liberty Fund, 1987.

. A arte de escrever ensaio e outros ensaios. Trad. e org. Marcio Suzuki e Pedro Paulo Pimenta. São

Paulo: Iluminuras, 2011.

. Ensaios políticos. Trad. Pedro Paulo Pimenta. São Paulo: Martins Fontes, 2003.

ÁRDAL. P. S. Passion and Value in Hume's Treatise. Edimburgo: Edinburg. University Press, 1989.

BAIER, A. A Progress of Sentiments. Harvard: Harvard University Press, 1991.

CLÉRO, J.-P. Hume. Une Philosophie des contradictions. Paris: Vrin, 1998.

DELEUZE, G. Empirisme et subjectivité. Paris: PUF, 1953.

FORBES, D. Hume's Pbilosophical Politics. Cambridge: Cambridge University Press, 1975.

MALHERBE, M. La Philosophie empiriste de David Hume. Paris: VRIN, 2001.

MICHAUD, Y. Hume et la fin de la philosophie. Paris: PUF, 1981.

STEWART, D. The Moral and Political Philosopby of David Hume, New York: Columbia University Press, 1963. 
TAYLOR, J. Reflecting subjects. Passion, Sympathy, and Society in Hume's Philosophy. Oxford: Oxford University Press, 2015.

"Sympathy, Self, and Others", In: The Cambridge Companion to Hume's Treatise, Ainslie, D. e Butler, A. (Ed.) Cambridge : Cambridge University Press, pp. 188-205, $2015 \mathrm{~b}$. 